\title{
温度补偿法解决二元气液平衡系统相图绘制实验中的分馏效应
}

宋丽平, 王亚婷, 郑欧 ${ }^{*}$, 吴舒婷, 祝淑颖, 陈建中

福州大学化学学院, 福州 350116

摘要: 通过改装二元气液平衡系统相图绘制实验的装置, 同时测定了环己烷-乙醇气液系统建立平衡时的沸点和露点 温度, 绘制并对比未保温、保温和温度补偿条件下的环己烷一乙醇气液相图。研究发现, 由于分馏效应的存在, 未保 温和简易保温情况下, 测得的溶液的沸点与露点两者温度均存在较大的差异, 利用沸点温度绘制的气相线存在严重 失真; 对系统进行了温度补偿后根据沸点和露点温度绘制的两条气相线能吻合较好, 即气相分馏效应得到了解决。

关键词: 物理化学; 气液相图绘制; 分馏效应; 温度补偿

中图分类号: G64; O6

\section{Temperature Compensation Method to Solve the Fractionation Effect in the Experiment of Binary Vapor-Liquid Equilibrium System Phase Diagram}

\author{
Liping Song, Yating Wang, Ou Zheng *, Shuting Wu, Shuying Zhu, Jianzhong Chen \\ College of Chemistry, Fuzhou University, Fuzhou 350116, P. R. China.
}

\begin{abstract}
In this paper, the device for phase diagram development experiment has been modified, which can be used to measure the boiling point and dew point of vapor-liquid equilibrium system simultaneously. In addition, the vapor-liquid phase diagrams of cyclohexane-ethanol under the conditions of no heat preservation, heat preservation and temperature compensation are drawn and compared. Results show that there is a great difference between the temperatures of boiling point and dew point both for the vapor-liquid equilibrium system with the simple heat preservation or without the heat preservation, and the vapor-phase lines based on the boiling point temperature are seriously distorted. With the temperature compensation for the system, the two vapor-phase lines according to the boiling point and the dew point temperature are in good agreement, which means the problem of vapor-phase fractionation effect has been solved.
\end{abstract}

Key Words: Physical chemistry; Vapor-liquid phase diagram drawing; Fractionation effect;

Temperature compensation

“双液系气液平衡相图” 实验项目是物理化学实验课程中的一个重要的基础实 ${ }^{2}$ 验 ${ }^{[1-10]}$ 。目前, 该实验项目国内各高校常用的设备是内置加热式沸点仪, 并可通过沸点法绘制相图 ${ }^{[2-6]}$, 其优点是操 作简单、减少爆沸且系统受热均匀。但由于气相分馏效应的存在 ${ }^{[2,3,11]}$, 获得准确的双液系相图并不 容易 ${ }^{[8-10]}$ 。前期实验工作观察发现, 若不采取保温措施, 纯的乙醇气液系统平衡时蒸馏瓶内气相的 温度分布存在一定的梯度 ${ }^{[11]}$, 造成了气相的分馏效应; 利用保温隔热套加速了系统建立气液平衡,

收稿: 2019-05-06; 录用: 2019-08-05; 网络发表: 2019-08-19

“通讯作者, Email: zhengouou@163.com

基金资助：国家自然科学基金项目(21775026); 福州大学一流本科教育改革项目(003698); 福州大学本科生科研训练项目（25071） 
减少蒸馏瓶内气相的温度分布梯度, 一定程度上降低了气相的分馏效应, 但未真正解决沸点和露点 温度是否一致的问题，因此不能判断沸点法绘制的相图是否准确。

本文在上述工作基础上改装实验仪器装置, 在环已烷-乙醇混合溶液建立的气液平衡过程中同时 监测系统的沸点和露点温度, 发现保温后露点温度与沸点温度差别仍很大, 继而对实验装置加装了 温度补偿系统, 温度补偿后沸点和露点温度吻合很好, 得到了较为理想的环己烷-乙醇二元气液平衡 相图。

\section{1 实验部分}

\section{1 仪器与试剂}

仪器: 沸点仪玻璃烧瓶 1 只(自制), FDY 双液系沸点测定仪 2 台(南京桑力电子设备厂), BSA223S 电子天平 1 台(赛多利斯), WYS- $2 \mathrm{~S}$ 数字阿贝折射仪 1 台(上海精密科学仪器有限公司), DC 低温恒 温槽 1 台(上海衡平仪器仪表厂), 加热套(杭州庚雨仪器有限公司), 保温盖(定制, 材质: FR-4 玻璃 纤维隔热板, 内祄: 石棉布), WK-SM3 智能温控器(科迪博), 玻璃沸点仪保温隔热套(手工缝制, 材 质：潜水布料，厚度： $3 \mathrm{~mm}$ )。

试剂：乙醇(AR，国药集团化学试剂有限公司)、环己烷(AR，国药集团化学试剂有限公司)。

\section{2 沸点仪器改进及装置示意图}

图 1 为改装的双温气液平衡系统仪器装置示意图, 蒸馏瓶中插上温度计 1 和 2 , 分别置于液面 下 $0.5 \mathrm{~cm}$ 和支管口位置, 同时监测系统的沸点和露点温度。

图 2 为改装的带温度补偿双温气液平衡系统仪器装置示意图, 与图 1 相比增加了恒温加热套对 系统进行温度补偿。如图 2 所示, 该补偿系统由智能控温器和加热套(带保温盖)组成, 其中温度计 3 为智能控温器的温度传感器的温度探头, 补偿加热电源由智能控温器输入, 实验时将根据温度计 2 (沸点)的数值设置补偿温度, 调节合适加热功率实现对气液平衡系统的空气浴恒温温度补偿。

仪器装置照片见支持材料。

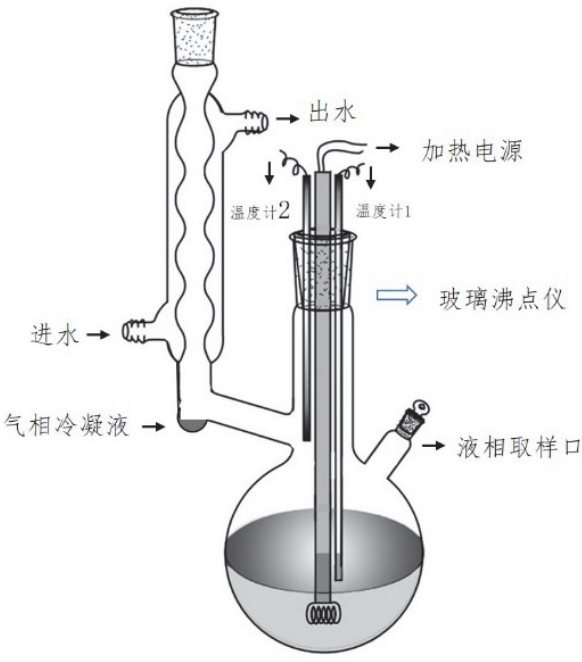

图 1 双温气液平衡系统仪器装置示意图

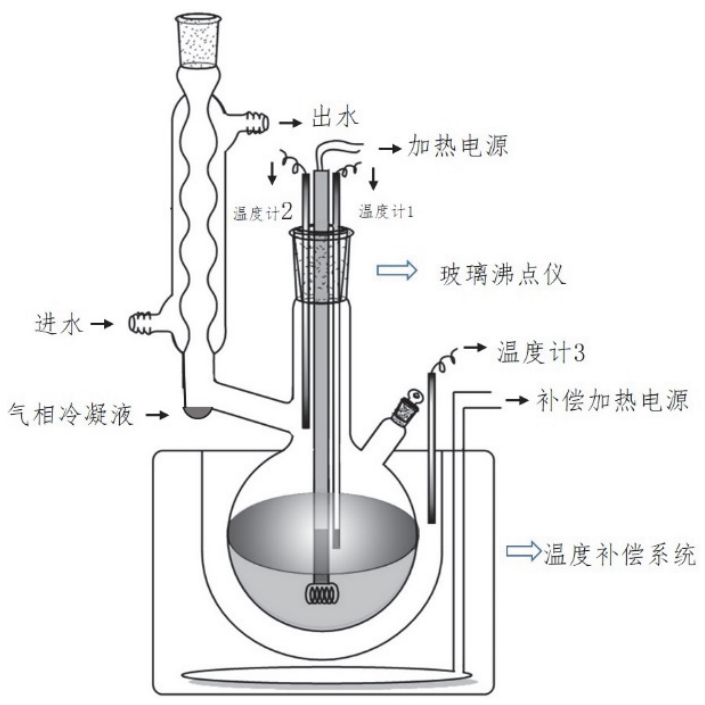

图 2 带温度补偿双温气液平衡系统仪器装置示意图

\section{3 实验内容和步骤}

\subsection{1 环己烷-乙醇溶液的折射率-组成工作曲线绘制}

用称量法准确配制乙醇的质量分数分别为 $0 、 0.1 、 0.2 、 0.3 、 0.4 、 0.5 、 0.6 、 0.7 、 0.8 、 0.9 、 1.0$ 
的一系列环己烷/乙醇溶液, 将阿贝折射仪连接高低温恒温水浴槽, 当温度恒定在 $25.0{ }^{\circ} \mathrm{C}$ 时, 测定 各溶液的折射率 $\left(n_{\mathrm{D}}^{25}\right)$ 。将溶液浓度换算成摩尔分数 $\left(x_{\mathrm{B}}\right)$, 绘制 $n_{\mathrm{D}}^{25}-x_{\mathrm{B}}$ 工作曲线并进行线性回归拟合。

\subsection{2 沸点仪温度计的误差测量}

如图 1 所示, 从洁净干燥的沸点仪液相取样口加入大约 $30 \mathrm{~mL}$ 的乙醇, 将温度计 1 和温度计 2 的探头末端同时伸入液面下 $0.5 \mathrm{~cm}$ 位置并保持与加热电阻丝之间一定距离, 打开冷凝水, 调节 FDY 双液系沸点测定仪的加热输出电压约 $13 \mathrm{~V}$ 左右, 使液体加热至缓缓沸腾, 待温度恒定时记下温度计 1 和温度计 2 显示值以及室内的大气压, 停止加热。将两仪器显示的温度与相应压力下乙醇的沸点 文献值比较得出沸点仪温度计的系统误差。

本文中沸点仪温度计测量的温度均经系统误差校准，详细操作见支持材料。

\subsection{3 环己烷-乙醇气液平衡系统相图的绘制}

测定不同组成溶液的沸点和露点温度(经系统误差和压力校准)以及气-液两相折射率 $n_{\mathrm{D}}^{25}$, 再从 $n_{\mathrm{D}}^{25}-x_{\mathrm{B}}$ 工作曲线上查得相应的组成, 然后绘制 $T_{0 \mathrm{~b}}-x_{\mathrm{B}}$ 图。

将大约 $30 \mathrm{~mL}$ 的乙醇从液相取样口加到沸点仪中, 加入适量的环已烷, 如图 1 调节好两只温度 计 1 和 2 的探头末端位置分别于液面下 $0.5 \mathrm{~cm}$ 和支管口位置。调节加热电压约 $13 \mathrm{~V}$ 左右, 使液体 加热至缓缓沸腾, 待温度恒定后分别记下 $1 、 2$ 两只温度计的温度值, 分别对应沸腾时液相和气相的 温度(即沸点和露点温度)。停止加热, 待液相停止沸腾时, 在冷凝管上口插入长吸液管吸取底部球形 凹槽内的气相冷凝液, 迅速测其折射率, 再用另一根短的吸管, 从沸点仪的加料口吸出液体迅速测 其折射率。

加入适量的环已烷, 重复上述操作, 得到另一组气液平衡的液相和气相的温度以及相应的气、 液相组分的折射率。重复上述操作, 继续逐次加入适量的环己烷直至环己烷加入约 $30 \mathrm{~mL}$, 得到一 半相图的数据。

同上, 先加大约 $30 \mathrm{~mL}$ 的环己烷至沸点仪中, 再逐次加入适量的乙醇, 测量另一半的数据。

为玻璃蒸馏瓶套上保温套, 重复上述步骤得到保温后的相图数据。

如图 2 所示, 将玻璃蒸馏瓶置于加热套中, 实验过程进行温度补偿(根据温度计 1 即环己烷-乙 醇溶液的沸点设定补偿温度), 相图数据测定同上。

实验原始数据及数据校准和计算过程详见支持材料。

\section{2 实验结果与讨论}

\section{1 环己烷-乙醇的 $T_{0 b}-X_{B}$ 相图绘制}

本实验中同时测定不同组成溶液的沸点和露点温度(经系统误差和压力校准)以及气-液两相折射 率 $n_{\mathrm{D}}^{25}$, 再从 $n_{\mathrm{D}}^{25}-x_{\mathrm{B}}$ 关系计算得到相应的组成, 然后绘制 $T_{0 \mathrm{~b}}-x_{\mathrm{B}}$ 图。其中环己烷-乙醇标准溶液的 $n_{\mathrm{D}}^{25}$

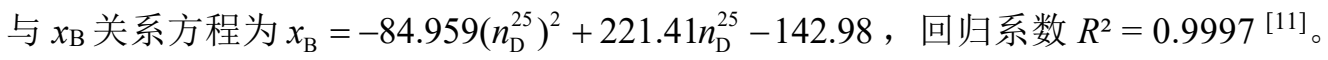

图 3a、3b、3c 分别为未保温、保温隔热及温度补偿的环己烷-乙醇的 $T_{0 \mathrm{~b}}-x_{\mathrm{B}}$ 图, 其中液相线根 据沸点绘制, 气相线 I 和气相线 II 分别是根据沸点温度和露点温度绘制的气相线。传统的双液系相 图绘制实验中, 气相线和液相线的绘制均使用沸点绘制, 如图 3 所示, 常规沸点法绘制的环己烷一乙 醇的 $T_{0 \mathrm{~b}}-x_{\mathrm{B}}$ 相图由液相线和气相线 $\mathrm{I}$ 组成, 三者求得的恒沸点均为 $\left(0.455,64.8^{\circ} \mathrm{C}\right)$ 与文献值 ${ }^{[12]}$ 一致。 对比三张图, 液相线无明显差异, 而三者的气相线存在着较大的差别。后面章节将详细讨论。

\section{2 传统沸点法绘制的环己烷-乙醇 $T_{0 b}-X_{B}$ 相图中气相线存在问题}

如前文 ${ }^{[11]}$ 所述, 由于热损失使得气相中形成一定的温度梯度并产生了分馏效应, 尽管保温处理 一定程度地改善了气相的分馏效应, 但不确定气相真实的温度即露点温度与沸点温度是否一致, 因 此无法证明分馏效应的消除。因此, 传统的双液系统相图绘制实验中, 气相线和液相线均根据沸点 温度绘制存在着问题。 

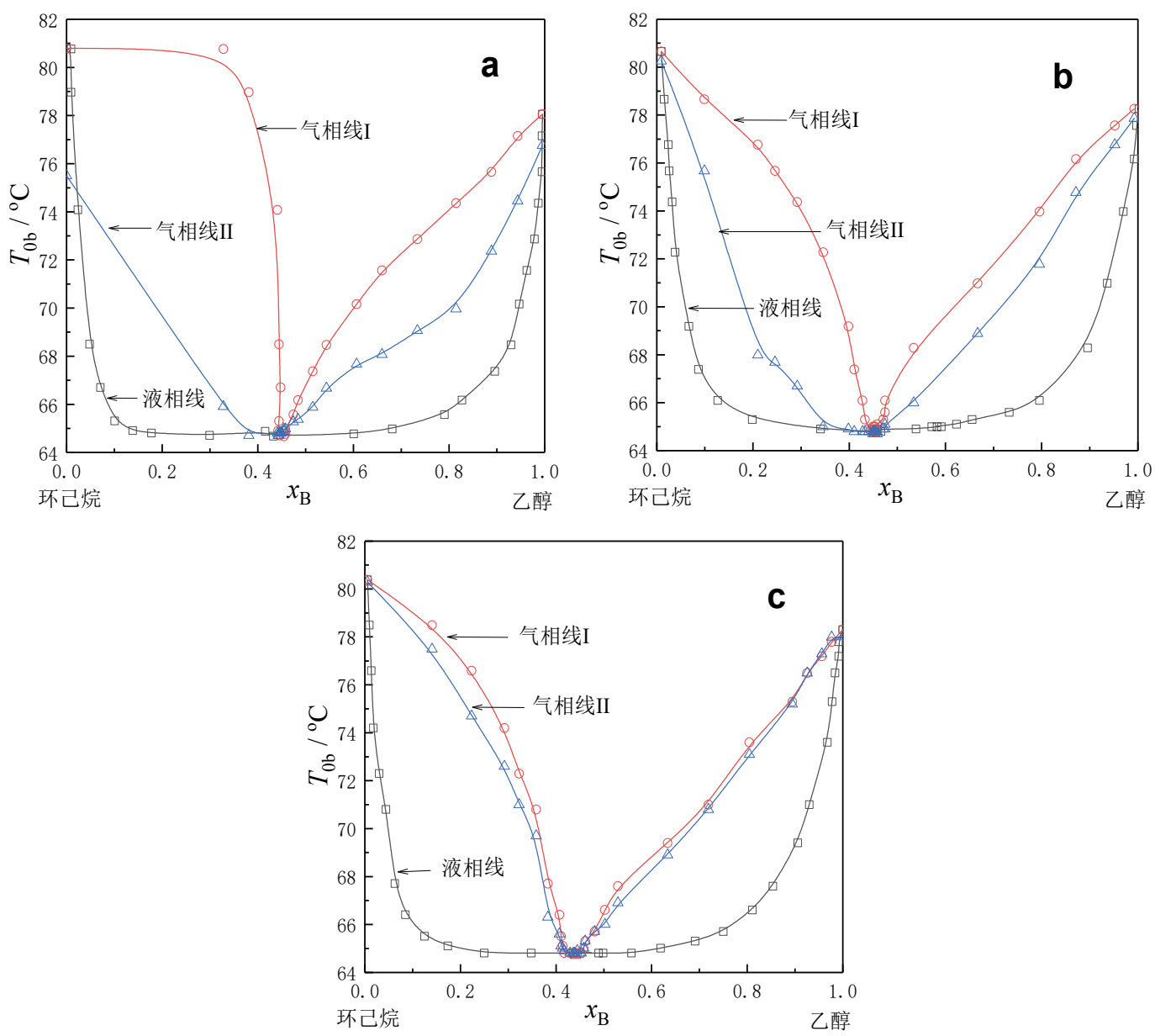

图 3 环己烷-乙醇二元系统的 $T_{0 b}-x_{\mathrm{B}}$ 关系图

气相线 I：根据沸点温度绘制; 气相线 II：根据露点温度绘制

(a) 未保温; (b) 保温; (c) 温度补偿

本文实验过程同时测定了气相和液相的温度, 如图 3(a)所示, 对比气相线 I 与气相线 II, 在未保 温情况下测得的露点温度远低于沸点温度, 尤其以环己烷为主的左边半张相图的露点温度点接近恒 沸温度, 例如: 当液相中乙醇含量仅为 0.009 时, 测得的实际气相露点温度为 $65.7^{\circ} \mathrm{C}$, 比沸点 $80.8^{\circ} \mathrm{C}$ 低了 $15.1^{\circ} \mathrm{C}$, 与恒沸点 $64.8^{\circ} \mathrm{C}$ 接近。保温之后, 如图 3(b)所示, 气相线 I 与气相线 II 的差异已得 到明显的改善, 但差距依然很大, 例如, 当液相中乙醇含量为 0.024 时, 测得实际气相露点的温度 为 $68^{\circ} \mathrm{C}$, 比沸点 $76.8^{\circ} \mathrm{C}$ 低了 $8.8^{\circ} \mathrm{C}$ 。尽管保温隔热套能减少玻璃沸点仪的热损失, 在一定程度上 降低系统中气相的分馏效应, 但却不能完全杜绝热损失, 因此最终也无法消除分馏效应, 沸腾时气 相的温度很难与沸点一致, 即保温之后气液平衡系统中分馏效应仍然严重, 显然沸点法绘制的相图 是不够准确的。

\section{3 温度补偿对环己烷-乙醇的相平衡过程分馏效应的有效控制}

根据上述结论, 在玻璃沸点仪外部增加了恒温加热套对气液平衡系统进行温度补偿, 装置如图 2 所示。实验过程, 根据温度计 1 测定到的沸点设定补偿的温度, 这样确保当液相沸腾过程中烧瓶 壁的温度不低于沸点, 有效的防止了气相中高沸点组分在烧瓶壁冷凝从而消除气相的分馏效应, 也 加速了气液平衡的建立。正如图 3(c)所示, 分别根据沸点和露点绘制的气相线 I 和气相线 II 能够较 好地吻合，表明温度补偿能够使气相的分馏效应得以有效的控制。 


\section{4 关于环己烷-乙醇的 $T_{0 \mathrm{~b}}-\mathrm{XB}_{\mathrm{B}}$ 相图实验中的其他说明}

在该实验中, 无论是未保温、保温隔热或温度补偿, 通过沸点法获得的环己烷-乙醇的 $T_{0 \mathrm{~b}}-x_{\mathrm{B}}$ 图 的恒沸点均为 $\left(0.455,64.8^{\circ} \mathrm{C}\right)$, 表明尽管分馏效应会导致绘制的相图失真, 但沸点法测定的恒沸点 是准确的，同时也反映了环己烷与乙醇形成的恒沸物的缔合组分较为稳定。

通过沸点法绘制环己烷-乙醇 $T_{0 \mathrm{~b}}-x_{\mathrm{B}}$ 相图, 在实验过程中如未采取任何保温措施, 绘制的 $T_{0 \mathrm{~b}}-x_{\mathrm{B}}$ 相图在恒沸点左边以环已烷为主的左边半张相图中非常容易呈现矩形状, 如图 3(a)气相线 I 与液相 线构成图所示; 而在恒沸点右边以乙醇为主的半张相图则无此现象。此现象反应了非极性的环己烷 与乙醇相比较易与环己烷/乙醇恒沸物分离, 前者表现出的分馏现象明显。

\section{3 结论}

传统利用沸点法绘制的气相线与真实的气相线存在较大的偏差。同时测定沸点和露点温度对气 相的分馏效应起了很好的监测作用。保温隔热套法能够一定程度降低分馏效应, 但未完全消除。新 增的温度补偿系统能够很好地防止气相的高沸点组分在烧瓶壁冷凝, 从而消除气相的分馏效应, 利 用改装后带温度补偿的沸点仪能够绘制较为准确的环己烷-乙醇气液相图。

补充材料: 可通过链接http://www.dxhx.pku.edu.cn免费下载。

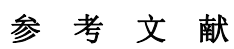

[1] Shoemaker, D. P.; Garland, C. W.; Nibler, J. W. Experiments in Physical Chemistry, 6th ed.; McGraw-Hill Book Co.: New York, 1996; pp. 207215.

[2] 复旦大学. 物理化学实验. 第3版. 北京: 高等教育出版社, 2004: 39-45.

[3] 南京大学. 物理化学实验. 北京: 高等教育出版社, 2010: 40-44.

[4] 韩国涁, 陈良坦, 李海燕, 袁汝明. 物理化学实验. 厦门: 厦门大学出版社, 2014: 61-67.

[5] 北京大学. 物理化学实验. 第4版. 北京: 北京大学出版社, 2002: 54-56.

[6] 高绍康. 基础化学实验. 北京: 化学化工出版社, 2013: 485-489.

[7] 清华大学. 基础物理化学实验. 北京: 高等教育出版社, 2008: 36-38.

[8] Kugel, R. W. J. Chem. Educ. 1998, 75 (9), 1125.

[9] Chen, F. M. C. J. Chem. Educ. 2005, 82 (7), 1100A.

[10] Boudreaux, A.; Campbell, C. J. Chem. Educ. 2012, 89 (6), 707.

[11] 郑欧, 张柏茂, 祝淑颖, 黄长沧, 吴舒婷, 李浩宏. 大学化学, 2018, $33(10), 85$.

[12] Horsley, L. H. Advances in Chemistry. Series 116. Azeotropic Data-III.; American Chemical Society: Washington D. C.,1973; p. 136. 